\title{
La autonomía del estudiante digital en la sociedad del conocimiento
}

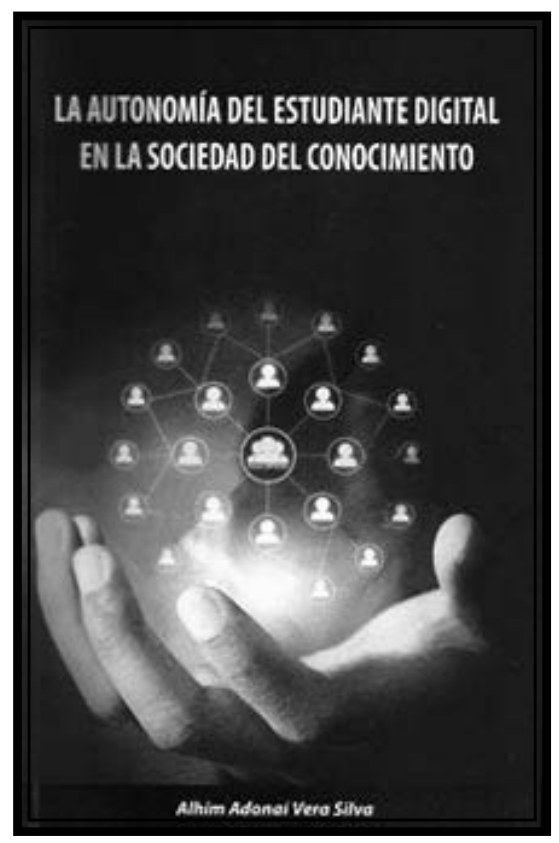

Alhim Adonai Vera Silva. (2017). La autonomía del estudiante digital en la sociedad del conocimiento. Bucaramanga: La Bastilla Soluciones Integrales.

El profesor Vera hizo un aporte novedoso en la comunidad académica colombiana interesada en los estudios de la gestión del conocimiento, al publicar en el 2007 un libro que reformulaba su tesis doctoral, Redes de cooperación científica en América Latina y el Caribe y en donde anticipaba de alguna forma los procesos de gestión académica atravesados por los imperativos de la era de la información. Así pues, en su momento se pensó que la oportunidad que tenían los países latinoamericanos de concertar un modelo educativo de desarrollo sustentable, sostenible y solidario con redes abiertas al planeta y en donde primara la investigación por el bienestar personal, económico, cultural, ambiental y de calidad de vida. Y la proyección de dicho deseo se concreta en el presente libro permitiéndonos ver que el autor defiende la tesis de que "la educación del siglo XXI liberará al estudiante digital [esto es el estudiante de la sociedad del conocimiento EE] de las ataduras de la verticalidad de los métodos confesionales, dogmáticos y rígidos y le permitirá: autocontrolarse, autorealizarse, autoeducarse, autogobernarse, autodeterminarse, en esencia ejercer la plenitud de la autonomía en su construcción individual y colectiva". (p. 18).

Se resume el contenido del libro en la sección 'Presentación' (pp. 7-11) que adaptamos para la presente reseña.

El capítulo 1, 'El surgimiento de la sociedad del conocimiento', aborda temas desde el hombre del paleolítico hasta el posmoderno, presenta rasgos esenciales de la educación en distintas épocas y culmina con la sociedad del conocimiento. Se está frente a un fenómeno desconcertante, las fronteras entre ciencias, tecnologías y artes, comienzan a disolverse, danza la magia de la 'diversidad en la unidad' y la 'unidad en la diversidad', con transformaciones inéditas en la comunicación interactiva que permite el ejercicio de la autonomía del estudiante digital en la sociedad del conocimiento. 
El capítulo 2, 'Estado, economía y poder en la sociedad del conocimiento' abre la tesis de la globalización, el papel del Estado-nación globalizante y del Estado-nación globalizado.

El capítulo 3, ‘El paso de la organización vertical a la organización horizontal' centra su análisis en la presencia de las redes de la sociedad del conocimiento tal y como la describe Drucker (1988).

El capítulo 4, ‘La modificación del tiempo y el espacio en las redes' describe las implicaciones de los conceptos tiempo y espacio vistos desde la sociedad-red que reconoce que la transformación del tiempo y el espacio bajo el paradigma de la revolución científica y tecnológica de las TIC es uno de los cimientos dela nueva sociedad-red.

El capítulo 5, 'la transformación del conocimiento' propone el modelo de conversión del conocimiento del conocimiento de Nonaka y Takeuchi (1995).

El capítulo 6, 'El conocimiento y la comunicación en la red' revive el 20 de julio de 1969, día que el hombre dio el primer paso en la luna, un portentoso paso de las cavernas a la comunicación intersatelital, de la sociedad industrial a la sociedad del conocimiento, de la enseñanza vertical al aprendizaje horizontal.
El capítulo 7, ‘Pedagogías, tecnologías y psicologías emergentes' anuncia que se están presentando rupturas entre la educación vertical, autoritaria, -enrejada- y la educación autónoma, horizontal, en red -enredada- con los soportes teóricos de la escuela activa de finales de los siglos XIX y XX y comienzos del XXI.

El capítulo 8, 'La unidad del conocimiento consilience' presenta este tipo de conocimiento como una estrategia nueva de integración entre las ciencias naturales, las ciencias sociales y las ciencias humanas, las tecnologías y el arte en la solución de problemas de la realidad.

Finalmente, el capítulo 9, 'Estrategias para el aprendizaje autónomo del estudiante digital' presenta generalidades del aprendizaje basado en: problemas, proyectos y casos sin desconocer que existen otros relevantes como los basados en retos y potencialidades.

Se cierra el libro con una reflexión que cuestiona: El principal cambio es reconocer que se está pasando de un paradigma centrado en la enseñanza a un paradigma centrado en el aprendizaje donde el ejercicio de la autonomía del estudiante digital es vital para desarrollar su creatividad frente a la complejidad de la sociedad del conocimiento.

Equipo editorial Entornos 